\title{
Papers
}

\section{A randomised multicentre trial of integrated versus standard treatment for patients with a first episode of psychotic illness}

Lone Petersen, Pia Jeppesen, Anne Thorup, Maj-Britt Abel, Johan Øhlenschlæger, Torben Østergaard Christensen,

Gertrud Krarup, Per Jørgensen, Merete Nordentoft

\begin{abstract}
Objectives To evaluate the effects of integrated treatment for patients with a first episode of psychotic illness.

Design Randomised clinical trial.

Setting Copenhagen Hospital Corporation and Psychiatric Hospital Aarhus, Denmark.

Participants 547 patients with first episode of schizophrenia spectrum disorder.

Interventions Integrated treatment and standard treatment. The integrated treatment lasted for two years and consisted of assertive community treatment with programmes for family involvement and social skills training. Standard treatment offered contact with a community mental health centre.

Main outcome measures Psychotic and negative symptoms (each scored from 0 to a maximum of 5) at one and two years' follow-up.

Results At one year's follow-up, psychotic symptoms changed favourably to a mean of 1.09 (standard deviation 1.27) with an estimated mean difference between groups of $-0.31(95 \%$ confidence interval -0.55 to $-0.07, \mathrm{P}=0.02$ ) in favour of integrated treatment. Negative symptoms changed favourably with an estimated difference between groups of -0.36 ( -0.54 to $-0.17, \mathrm{P}<0.001)$ in favour of integrated treatment. At two years' follow-up the estimated mean difference between groups in psychotic symptoms was $-0.32(-0.58$ to $-0.06, \mathrm{P}=0.02)$ and in negative symptoms was -0.45 ( -0.67 to $-0.22, \mathrm{P}<0.001)$, both in favour of integrated treatment. Patients who received integrated treatment had significantly less comorbid substance misuse, better adherence to treatment, and more satisfaction with treatment.

Conclusion Integrated treatment improved clinical outcome and adherence to treatment. The improvement in clinical outcome was consistent at one year and two year follow-ups.
\end{abstract}

\section{Introduction}

Certain psychosocial treatments have been shown to have beneficial effects on clinical and social outcomes for patients with schizophrenia: for example, assertive community treatment improved independent living, affiliation into the labour market, satisfaction with treatment, and use of bed days for patients with severe mental illness, ${ }^{1}$ and family intervention reduced rates of relapse. ${ }^{2}$ It has also been suggested that early treatment after the onset of psychotic illness provides the best chance of preventing relapse. ${ }^{34}$

Our study (the OPUS trial) is the first large randomised clinical trial of integrated treatment versus standard treatment for patients who had experienced a first episode of psychosis. ${ }^{5}$ The null hypothesis investigated was that there would be no differences between integrated treatment and standard treatment with regard to psychotic and negative symptoms, treatment adherence, admissions, use of bed days, substance abuse, accommodation status, labour market affiliation, and user satisfaction.

\section{Participants and methods}

\section{Patients}

Patients were included from all inpatient and outpatient mental health services in Copenhagen (Copenhagen Hospital Corporation) and Aarhus County. From January 1998 until December 2000, 547 patients aged 18-45 years with a diagnosis in the schizophrenia spectrum ((ICD-10 codes in the F2 category) and who had not been given antipsychotic drugs for more than 12 weeks of continuous treatment were included in the trial.

\section{Randomisation}

The included patients were centrally randomised to integrated treatment or standard treatment. In Copenhagen, randomisation was carried out through centralised telephone randomisation at the Copenhagen Trial Unit. The allocation sequence was computer generated, 1:1, in blocks of six, and stratified for each of five centres. In Aarhus, the researchers contacted a secretary by telephone when they had finished the entry assessment of each patient. The secretary then drew one lot from among five red and five white lots out of a black box. When the block of 10 was used, the lots were redrawn. Block sizes were unknown to the investigators.

\section{Interventions}

The trial was pragmatic, comparing integrated treatment defined by a set of protocols with treatment as usual. ${ }^{6}$

\section{Integrated treatment}

This was as assertive community treatment ${ }^{7}$ enhanced by better specific content via family involvement and social skills training. Two multidisciplinary teams in Copenhagen and one in Aarhus were established and trained to provide integrated treatment. Caseload reached a level of about 10. Each patient was offered integrated treatment for a period of two years. A primary team member was designated for each patient and was then responsible for maintaining contact and coordinating treatment within the team and across different treatment and support facilities. Patients were visited in their homes or other places in their community or at their primary team member's office according to their preference. During hospitalisation, treatment responsibility 
was transferred to the hospital, but a team member visited the patient once a week. The office hours were Monday to Friday, 8 am to $5 \mathrm{pm}$. All team members had a mobile phone with an answering function. Outside office hours, patients could leave a message and be sure that the team would respond the next morning. A crisis plan was developed for each patient. If the patient was reluctant about treatment, the team stayed in contact with the patient and tried to motivate the patient to continue treatment

The fidelity of the programme, measured with the index of fidelity of assertive community treatment, ${ }^{8}$ was $70 \%$ in both Copenhagen and Aarhus. The factors responsible for the reduced fidelity were time limited treatment, 24 hour coverage in other settings, and about two contacts weekly with each patient, patient's family, and collaborating partners.

Psychoeducational family treatment was offered, and team members always tried to make contact with at least one family member and motivate patients and families to participate in a psychoeducational group. Family treatment followed McFarlane's manual for psychoeducational treatment for multiple family groups ${ }^{9}$ and included 18 months of treatment, 1.5 hours twice weekly, in a multiple family group with two therapists and four to six patients with their families. The multiple family group focused on problem solving and development of skills to cope with the illness.

Patients' social skills were assessed using the World Health Organization's psychiatric disability assessment. ${ }^{10}$ Patients with impaired social skills were offered social skills training focusing on medication, coping with symptoms, conversation, and problem solving skills in a group of maximum six patients and two therapists. ${ }^{11}$

\section{Standard treatment}

Standard treatment usually offered the patient treatment at a community mental health centre. Each patient was usually in contact with a physician, a community mental health nurse, and in some cases also a social worker. Home visit was possible, but office visits were the general rule. A staff member's caseload in the community mental health centres varied between 1:20 and 1:30. Outside office hours, patients could refer themselves to the psychiatric emergency room.

\section{Antipsychotic drugs}

Patients in both treatment groups were offered antipsychotic drugs according to guidelines from the Danish Psychiatric Society, which recommend a low dose strategy for patients with a first episode of psychotic illness and use of second generation antipsychotic drugs as first choice.

\section{Assessments}

Only independent investigators (PiJ, MA, PK, RM, LP, AT, TC, JØ) were involved in follow-up interviews. For practical reasons, they could not be kept blind to treatment allocation. At study entry and at the one and two year follow-ups, the following information was collected:

- Main diagnosis and comorbidity based on the schedule for clinical assessment in neuropsychiatry (SCAN 2.0 in 1998, SCAN 2.1 since 1999) $)^{12}$

- Scale for assessment of positive symptoms (SAPS) and scale for assessment of negative symptoms (SANS). ${ }^{13}$ The scales are summed up in three dimensions (psychotic, negative, and disorganised) with values ranging from 0 to $5^{14}$

- Sociodemographic factors
- Global assessment of functioning, function and symptoms (GAF)

- Social network schedule ${ }^{15}$

- Client satisfaction questionnaire. This is a ranking scale based on eight questions with four answering categories added together for a total score ${ }^{16}$

- Suicide attempts and suicidal ideation based on self reporting $^{17}$

- Duration of untreated psychosis, assessed with the interview for retrospective assessment of onset of schizophrenia ${ }^{18}$

We used algorithms to investigate whether patients fulfilled the general criteria for depression in ICD-10. The algorithms were based on selected items in the section in SCAN that covered depressed mood and ideation, thinking, concentration, energy, interests, and bodily functions, and for which patient data were available.

\section{Other data sources}

Information about use of bed days was available from official registers for all patients (except those who died or emigrated). We used patients' full medical records as data source for service use (besides bed days), use of antipsychotic drugs, and treatment adherence.

\section{Inter-rater reliability}

All investigators were trained in the SCAN interview at the WHO collaborating centre and trained once every second month in SAPS (for assessing positive symptoms) with live interviews. At the end of the trial LP, JO, GK, TC, and AT did 14 reliability interviews for SANS (for assessing negative symptoms) and 12 for SAPS. Intra-class correlation coefficient was 0.54 for the negative dimension (moderate agreement) and 0.88 for the psychotic dimension (very good agreement). ${ }^{19}$

\section{Statistical methods}

Attrition to the two year follow-up interview was skewed: $75 \%$ of the patients randomised to integrated treatment attended the interview compared with only $60 \%$ of control patients (see figure). In order to assess the influence of missing data on the one and two year outcome measures, we subjected the data on SAPS, SANS, and GAF (global assessment of functioning) to further analysis in a repeated measurements model with unstructured variance matrix. This approach assumed that the distribution of missing data could be estimated from the information from previous interviews. The condition for using this method is the assumption that data were missing at random when taking into consideration the information extracted from the baseline and one year follow-up interviews. Covariates entered in the repeated measurements model were treatment, sex, substance misuse, and treatment site. Accounting for the baseline value was automatic since it is included in the model, and no treatment effect was allowed for at baseline. An alternative approach to manage the skewed attrition is sensitivity analyses, which we also carried out.

We calculated odds ratios for treatment effect with logistic regression analyses, with treatment site (Copenhagen and Aarhus) included as covariates. When possible, we also included the baseline value of the variable as covariate.

We assessed differences in continuous variables (client satisfaction questionnaire) using analysis of variance, with treatment sites included as covariates. We used Mann-Whitney's $\mathrm{U}$ test to test differences in continuous data with skewed distribution. All statistical analyses were done with SPSS 11.0 (Statistical Package, 2000). 
Power calculation

When the trial was planned, we considered relapse to be the primary outcome measure, and we intended to assess each patient every third month for positive symptoms with SAPS interviews. However, since participation in these interviews was only about 60\%, we decided in September 1999 to use psychotic and negative symptoms at one and two year follow-up as the primary outcome measures. We analysed these outcome measures on the basis of intention to treat. We expected that the mean reduction of psychotic symptoms measured by SAPS would be one point for the patients allocated standard treatment with standard deviation of 1.3. As a minimum, we wanted to be able to detect a $50 \%$ greater reduction in psychotic symptoms in the experimental group at the 0.05 level of significance and with power of 0.9 . Using Pocock's formula, ${ }^{20}$ we calculated that we required 142 patients for each study group and that, to compensate for $20 \%$ attrition during follow-up, 178 patients should be included in each group.

\section{Results}

\section{Baseline characteristics}

Table 1 summarises the results of the baseline interview. The two treatment groups had no significant differences in their baseline characteristics.

\section{Attrition from study}

The figure shows the patient flow through the study, and the attrition from it. We found no significant difference in baseline measures between those patients who participated in the follow-up interviews and those who did not, except that patients from Aarhus and patients with a relative attending the baseline interview in both treatment groups were more likely to attend the follow-up interview. In the control group, patients who had not completed high school and those with substance misuse diagnosed at baseline interview were less likely to participate in the follow-up interviews.

\section{Main outcomes}

Table 2 shows the clinical outcomes and user satisfaction in the two treatment groups. Integrated treatment was significantly better than standard treatment with regard to both psychotic symptoms and negative symptoms. There were no differential treatment effects between the two sites. The estimated effect of integrated treatment versus standard treatment on the psychotic symptoms was equal to every third patient in the integrated treatment group gaining one point (from "severe" to "marked" or from "moderate" to "mild") when measured with the SAPS scale. The effect on negative symptoms is equal to every second patient in integrated treatment gaining one point compared with standard treatment. This is of clinical importance.

Integrated treatment also resulted in significantly greater patient satisfaction, and this difference between treatment groups was larger at two year follow-up than at one year. Cohen's $d$ standardised effect size for client satisfaction was 0.69 , which is fairly large.

Sensitivity analyses of psychotic and negative symptoms

Because of the skewed attrition (figure), we tested two different assumptions about the patients who did not participate in the two year follow-up interview. The less favourable prognostic factors among non-participants compared with participants suggest that non-participants as a group fared worse. Thus, we carried forward the non-participants' baseline values and one year values (if available) for the psychotic and negative
Table 1 Sociodemographic and clinical characteristics of 547 patients with a first episode of psychotic illness at entry into trial of integrated treatment versus standard treatment. Values are numbers (percentages) unless stated otherwise

\begin{tabular}{|c|c|c|}
\hline & $\begin{array}{c}\text { Integrated } \\
\text { treatment } \\
(n=275)^{\star}\end{array}$ & $\begin{array}{c}\text { Standard } \\
\text { treatment } \\
(\mathrm{n}=272)^{*}\end{array}$ \\
\hline \multicolumn{3}{|l|}{ Sociodemographic characteristics } \\
\hline Male & $159(58)$ & $164(60)$ \\
\hline Mean (SD) age (years) & $26.6(6.4)$ & $26.6(6.3)$ \\
\hline Brought up with both parents & $175(64)$ & $175(66)$ \\
\hline Having an intimate relationship & $57(21)$ & $76(29)$ \\
\hline Married & $16(6)$ & $14(5)$ \\
\hline Being a parent & $42(15)$ & 37 (14) \\
\hline Completed high school education & $98(36)$ & $83(31)$ \\
\hline \multicolumn{3}{|l|}{ Vocational education: } \\
\hline None & $163(60)$ & $156(59)$ \\
\hline In education & $38(14)$ & $31(12)$ \\
\hline Short education, skilled & $54(20)$ & $52(20)$ \\
\hline Longer education & $17(6)$ & $24(9)$ \\
\hline \multicolumn{3}{|l|}{ Living conditions: } \\
\hline Living alone, with partner or child & $208(76)$ & $213(80)$ \\
\hline Living with parents & $49(18)$ & $41(15)$ \\
\hline Living in supervised setting & $1(0)$ & $2(1)$ \\
\hline Homeless & $14(5)$ & $10(4)$ \\
\hline Inpatient at randomisation & $117(43)$ & $127(47)$ \\
\hline \multicolumn{3}{|l|}{ Clinical characteristics } \\
\hline Median duration of untreated psychosis (weeks) $†$ & 46 & 53 \\
\hline \multicolumn{3}{|l|}{ Diagnosis: } \\
\hline Schizophrenia & $185(67)$ & $177(65)$ \\
\hline Schizotypal disorder & $42(15)$ & $37(14)$ \\
\hline Delusional disorder & $12(4)$ & $13(5)$ \\
\hline Brief psychosis & $19(7)$ & $26(10)$ \\
\hline Schizoaffective disorder & $10(4)$ & $15(5)$ \\
\hline Unspecified non-organic psychosis & $7(2)$ & $4(1)$ \\
\hline \multicolumn{3}{|l|}{ Psychopathology scoresł: } \\
\hline Psychotic dimension & $2.8(1.4)$ & $2.6(1.4)$ \\
\hline Negative dimension & $2.2(1.2)$ & $2.2(1.2)$ \\
\hline Disorganised dimension & $1.0(0.9)$ & $1.0(1.0)$ \\
\hline \multicolumn{3}{|l|}{ Comorbidity: } \\
\hline Diagnosis of harm or dependence syndrome & $73(27)$ & $73(27)$ \\
\hline \multicolumn{3}{|l|}{ Suicidal behaviour and ideation: } \\
\hline Suicide attempt ever & $82(32)$ & $77(31)$ \\
\hline Suicide attempt last year & $48(21)$ & $52(23)$ \\
\hline Suicidal plans at least once last week & $29(12)$ & $25(11)$ \\
\hline Suicidal thoughts at least once last week & $58(25)$ & $65(28)$ \\
\hline Thoughts that life is not worth living, at least once last week & $93(39)$ & $94(40)$ \\
\hline \multicolumn{3}{|l|}{ Social functioning: } \\
\hline Mean (SD) GAF symptoms & $32.7(10.3)$ & $34.4(11.0)$ \\
\hline Mean (SD) GAF function & $41.6(13.6)$ & $41.0(13.1)$ \\
\hline Median No of friends & 2 & 2 \\
\hline Median No of friends and family & 7 & 6 \\
\hline
\end{tabular}

\section{GAF=Global assessment of functioning}

*Not all participants responded to all questions

†Duration of untreated psychosis was only assessed for patients not diagnosed with schizotypal disorder and schizophrenia simplex $(\mathrm{N}=429)$.

fScores on assessment scales with values ranging from 0 to 5 .

dimensions to the two year follow-up. This resulted in integrated treatment having an even greater positive effect on both psychotic and negative symptoms (data not shown).

The other (less likely) assumption was that non-participants had experienced a total remission of psychotic and negative symptoms. On this basis, we set their psychotic and negative dimensions at two years to zero, and the positive effect of integrated treatment on the psychotic and negative dimensions became non-significant. 
Table 2 Clinical outcomes and user satisfaction of patients with a first episode of psychotic illness who received integrated treatment or standard treatment. Values are means (SD) unless stated otherwise

\begin{tabular}{|c|c|c|c|c|c|c|c|c|}
\hline & \multicolumn{4}{|c|}{1 year follow-up ( $n=419$ ) } & \multicolumn{4}{|c|}{2 year follow-up (n=369) } \\
\hline & $\begin{array}{c}\text { Integrated } \\
\text { treatment } \\
(\mathrm{n}=227)\end{array}$ & $\begin{array}{l}\text { Standard } \\
\text { treatment } \\
(n=192)\end{array}$ & $\begin{array}{c}\text { Estimated mean } \\
\text { difference }(95 \% \mathrm{CI})\end{array}$ & $\begin{array}{l}P \text { value of } \\
\text { difference }\end{array}$ & $\begin{array}{c}\text { Integrated } \\
\text { treatment } \\
(\mathrm{n}=205)\end{array}$ & $\begin{array}{l}\text { Standard } \\
\text { treatment } \\
(n=164)\end{array}$ & $\begin{array}{c}\text { Estimated mean } \\
\text { difference }(95 \% \mathrm{CI})\end{array}$ & $\begin{array}{l}P \text { value of } \\
\text { difference }\end{array}$ \\
\hline \multicolumn{9}{|l|}{ Psychopathology*: } \\
\hline Psychotic dimension & $1.09(1.27)$ & $1.35(1.39)$ & $-0.31(-0.55$ to -0.07$)$ & 0.02 & $1.06(1.26)$ & $1.27(1.40)$ & $-0.32(-0.58$ to -0.06$)$ & 0.02 \\
\hline Negative dimension & $1.68(1.10)$ & $2.02(1.12)$ & $-0.36(-0.54$ to -0.17$)$ & $<0.001$ & $1.41(1.15)$ & $1.82(1.23$ & $-0.45(-0.67$ to -0.22 & $<0.001$ \\
\hline Disorganised dimension & $0.40(0.59)$ & $0.42(0.56)$ & $-0.04(-0.14$ to 0.07$)$ & 0.5 & $0.37(0.56)$ & $0.50(0.73)$ & $-0.12(-0.25$ to 0.00$)$ & 0.06 \\
\hline GAF, symptom & $48.2(14.9)$ & $44.9(16.0)$ & 3.00 (0.37 to 5.63$)$ & 0.03 & $51.18(15.01)$ & 48.67 (15.92) & $2.45(-0.32$ to 5.22$)$ & 0.08 \\
\hline GAF, function & $51.7(15.1)$ & $49.4(14.6)$ & 2.61 (0.11 to 5.15) & 0.04 & $55.16(15.15)$ & 51.13 (15.92) & 3.12 (0.37 to 5.88$)$ & 0.03 \\
\hline User satisfaction† & $24.9(4.5)$ & $23.0(7.2)$ & 1.88 (0.73 to 3.02$)$ & 0.001 & $26.1(3.7)$ & $22.9(5.2)$ & 3.09 (2.10 to 4.04$)$ & $<0.001$ \\
\hline
\end{tabular}

GAF=global assessment of functioning.

*Estimated mean differences are based on a repeated measurements model with treatment site, sex, substance misuse, diagnosis at baseline, and baseline values of the scale included as covariates (see text for details).

†Based on client satisfaction questionnaire score. Estimated mean differences calculated by analysis of variance with treatment site as covariate.

\section{Comorbidity and social outcomes}

Integrated treatment significantly reduced substance misuse both at one year and two year follow-up, but it had no significant effect on depression or suicidal behaviour and ideation (table 3).

A significantly smaller proportion of patients given integrated treatment did not live independently at one year follow-up compared with patients given standard treatment $(10 \% v 17 \%)$, but not at two year follow-up (13\% v 14\%) (table 3). At one year follow-up significantly more of the patients given integrated treatment than those given standard treatment were attending a rehabilitation programme $(14 \% v 7 \%)$, but at two years the difference was not significant $(17 \% v 12 \%)$.

\section{Non-adherence to treatment}

During the first year, patients were significantly less likely to discontinue integrated treatment for at least a month than standard treatment $(8 \% v 22 \%)$ (table 4). Integrated treatment was also clearly superior to standard treatment when non-adherence was measured in terms of treatment discontinued in spite of need $(3 \% v 15 \%)$ or in terms of not making any outpatient visits $(3 \% v$ $15 \%$ in first year, $7 \%$ v $31 \%$ in second year) (table 4 ).

\section{Use of health services and antipsychotic drugs}

From official registers, we found that patients given integrated treatment spent significantly fewer days in hospital in the first year than did patients given standard treatment (mean 62 days $v$ 79 days) (table 4). For the total intervention period, patients given integrated treatment used 22\% fewer bed days than those given standard treatment (mean 89 days $v 114$ days; difference $-25.0,95 \%$ confidence interval -51.0 to $1.1, \mathrm{P}=0.06$ ).

The proportion of patients receiving first or second generation antipsychotic drugs was not significantly different in the two treatment groups (table 4). To establish whether differences in antipsychotic medication in the two groups were responsible for the differences in psychotic and negative dimension, we analysed drug use by treatment allocation, treatment site, baseline value of scale, and use of second generation antipsychotics (or first and second generation, or first generation only). All analyses showed a significant positive effect of integrated treatment on psychotic and negative symptoms. Patients given integrated treatment received significantly lower doses of second generation antipsychotics (table 4).

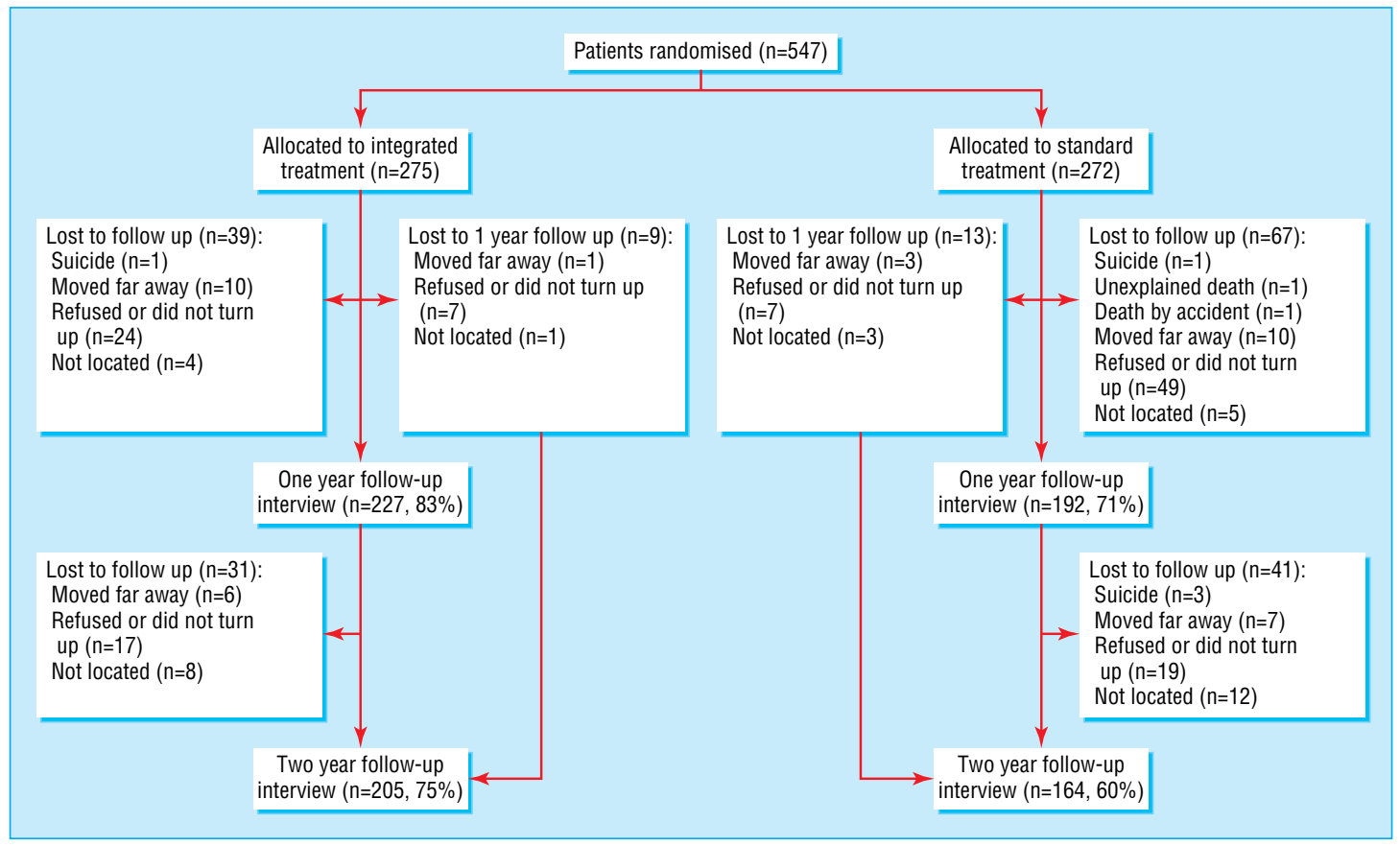

Patient flow through study 
Table 3 Comorbidity and social outcomes of patients with a first episode of psychotic illness who received integrated treatment or standard treatment. Values are percentages of patients unless stated otherwise

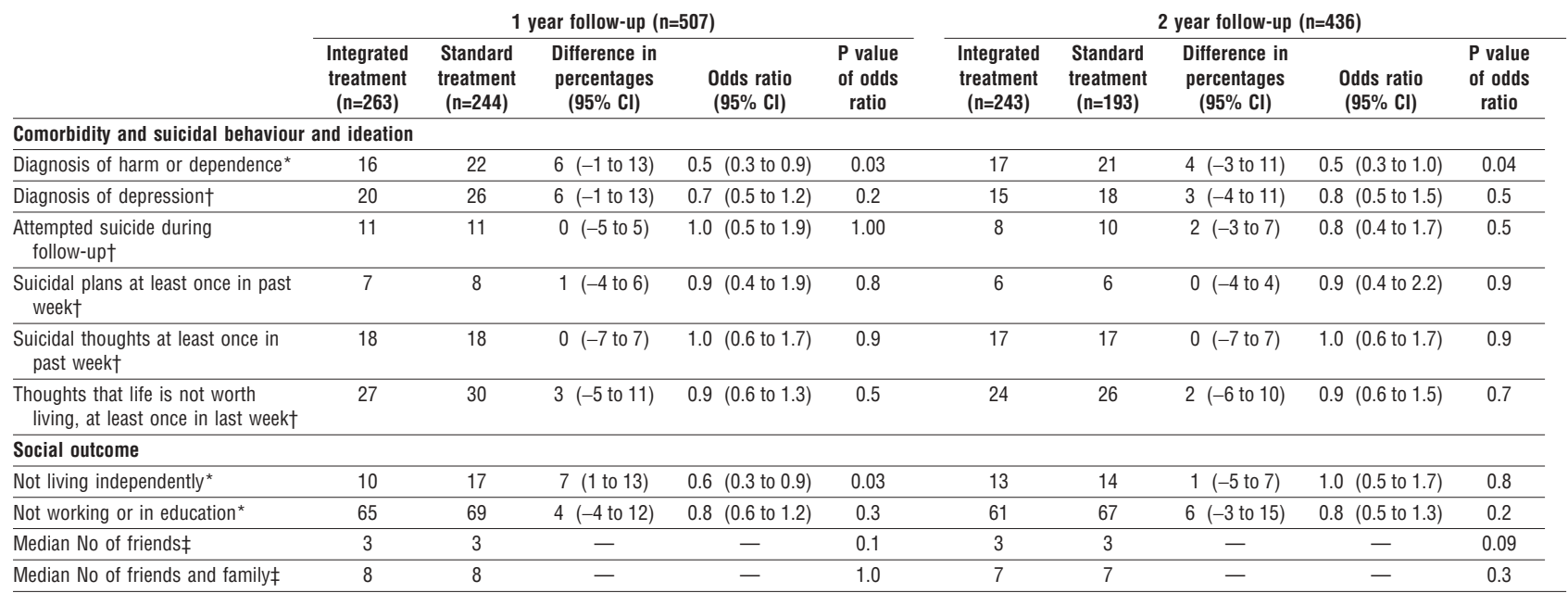

*Based on patients with full medical record. Odds ratios and $\mathrm{P}$ values based on logistic regression analyses with treatment site and baseline values included as covariates.

†Based on patients interviewed at follow up. Odds ratios and $\mathrm{P}$ values based on logistic regression analyses with treatment site included as covariate.

$\ddagger$ ‡ased on patients interviewed at follow up. Mann-Whitney’s non-parametric test for independent samples.

\section{Discussion}

\section{Patient outcomes}

The results of this large randomised trial favour integrated treatment, consisting of the assertive community treatment model enhanced by specific protocols for family involvement and social skills training, with regard to psychopathology, adherence to treatment, comorbid diagnosis of harm and dependence, client satisfaction, social outcomes (only first year), and use of health services. The positive effects on psychotic symptoms were not explained by differences in use of antipsychotic drugs. The results from the first year with regard to psychotic and negative symptoms were replicated in the second year, indicating robustness.

The effect of integrated treatment on psychotic and negative symptoms was smaller than the minimum effect we had assumed when calculating the sample size needed for the trail. If we calculate standardised measures of effect size such as Cohen's $d$, we find an effect size for psychotic symptoms of 0.19 (first year) and 0.16 (second year) and for negative symptoms of 0.31 (first year) and 0.34 (second year), which is considered medium. Calculations of Cohen's $d$ are based only on assessment of interviewed patients, and therefore possibly underestimate the difference between integrated treatment and standard treatment.

Drop-out analyses suggested that the patients not participating in the follow-up interviews had a poorer prognosis. Analyses of differential attrition in the two treatment groups indicate that more patients with poor outcome (substance misusers, patients with education only up to secondary school level) were interviewed in the integrated treatment group. This might mean that the effect of integrated treatment on substance misuse is larger than indicated in our results. It might also explain why the patients receiving integrated treatment did not have a significantly better social outcome than the patients given standard treatment in the two year follow-up.

The results concerning suicide attempts and suicidal ideation are not encouraging, and it is likely that specialised interventions such as 24 hour support and cognitive behaviour therapy might be required to get better results.

\section{Comparison with other studies}

Our findings are in accordance with the results from a meta-analysis of assertive community treatment for people with severe mental illness, ${ }^{1}$ with findings from naturalistic studies of integrated treatment, ${ }^{21-23}$ and with the results of the only other published randomised clinical trial of specialised care for patients with early psychosis. ${ }^{24}$

\section{Limitations of the study}

It was necessary to change our outcome measure from relapse to psychotic and negative symptoms, but this decision was made before the analyses of one year outcome were started.

Although interviewers were not involved in the treatment of patients, they were not blind to which treatment patients had been assigned. This may be associated with a biased rating of psychopathology. ${ }^{25}$ However, our findings about psychopathology are coherent with several other outcome measures that are less likely to be biased-for example, living conditions and health service use are outcome measures not vulnerable to information bias. Our analyses of use of bed days were not influenced by the differential attrition, as the analyses were based on complete information from the Danish Psychiatric Case Register.

In common with other studies of assertive community treatment, our trial might be biased because of skewed attrition, ${ }^{1}$ which is inevitable in controlled trials of treatments designed to increase treatment adherence. However, our analyses of attrition indicate that patients who did not attend two year follow-up interviews constituted a negatively selected subpopulation. This would be more likely to bias our results against integrated treatment than in favour of it.

\section{Conclusion}

Integrated treatment reduced psychotic and negative symptoms more than standard treatment. The effect was small but of clinical importance. Integrated treatment improved adherence to treatment. Integrated treatment adds substantial costs to treatment, but these would be counterbalanced by the reduced use of other health services that we found with this intervention.

Contributors: Professors Ralf Hemmingsen and Niels Reisbyt participated in designing the study and writing the initial application for funds. Profes- 
Table 4 Non-adherence to treatment, health service use, and antipsychotic drug use for patients with a first episode of psychotic illness who received integrated treatment or standard treatment. Values are percentages of patients unless stated otherwise

\begin{tabular}{|c|c|c|c|c|c|c|c|c|c|c|}
\hline & \multicolumn{5}{|c|}{1 year follow-up $(n=507)$} & \multicolumn{5}{|c|}{2 year follow-up ( $n=436)$} \\
\hline & $\begin{array}{c}\text { Integrated } \\
\text { treatment } \\
(\mathrm{n}=263)\end{array}$ & $\begin{array}{c}\text { Standard } \\
\text { treatment } \\
(n=244)\end{array}$ & $\begin{array}{l}\text { Difference in } \\
\text { percentages } \\
(95 \% \mathrm{CI})\end{array}$ & $\begin{array}{l}\text { Odds ratio } \\
(95 \% \mathrm{Cl})\end{array}$ & $\begin{array}{l}P \text { value of } \\
\text { difference }\end{array}$ & $\begin{array}{c}\text { Integrated } \\
\text { treatment } \\
(\mathrm{n}=243)\end{array}$ & $\begin{array}{c}\text { Standard } \\
\text { treatment } \\
(\mathrm{n}=193)\end{array}$ & $\begin{array}{c}\text { Difference in } \\
\text { percentages } \\
(95 \% \mathrm{Cl})\end{array}$ & $\begin{array}{l}\text { Odds ratio } \\
(95 \% \mathrm{Cl})\end{array}$ & $\begin{array}{l}P \text { value of } \\
\text { difference }\end{array}$ \\
\hline \multicolumn{11}{|l|}{ Non-adherence during follow-up } \\
\hline $\begin{array}{l}\text { Treatment discontinued for } \geq 1 \\
\text { month }^{\star}\end{array}$ & 8 & 22 & 14 (8 to 22) & 0.3 (0.2 to 0.6$)$ & $<0.001$ & 12 & 14 & $2(-4$ to 8$)$ & $0.9(0.5$ to 1.5$)$ & 0.6 \\
\hline $\begin{array}{l}\text { Treatment stopped in spite of } \\
\text { need }^{*}\end{array}$ & 3 & 15 & 12 (7 to 17$)$ & $0.2(0.1$ to 0.4$)$ & $<0.001$ & 4 & 6 & $2(-2$ to 6$)$ & 0.6 (0.3 to 1.5$)$ & 0.3 \\
\hline No outpatient visits* & 4 & 15 & 11 (6 to 16) & 0.3 (0.1 to 0.5$)$ & $<0.001$ & 7 & 31 & 24 (17 to 31$)$ & $0.2(0.1$ to 0.3$)$ & $<0.001$ \\
\hline \multicolumn{11}{|l|}{ Service use } \\
\hline \multicolumn{11}{|l|}{ During follow-up: } \\
\hline $\begin{array}{l}\text { Mean (SD) No of days in } \\
\text { hospital } \dagger\end{array}$ & $62.2(94.6)$ & $78.9(104.0)$ & - & $\begin{array}{c}-16.8 \\
(-33.5 \text { to }-0.05)\end{array}$ & $<0.05$ & $\begin{array}{l}26.8 \\
(73.2)\end{array}$ & $\begin{array}{l}34.8 \\
(79.6)\end{array}$ & - & $\begin{array}{c}-8.1 \\
(-21.0 \text { to } 4.8)\end{array}$ & 0.2 \\
\hline $\begin{array}{l}\text { Median No of days in } \\
\text { hospitalł }\end{array}$ & 14 & 40 & - & - & 0.02 & 0 & 0 & - & - & \\
\hline Not hospitalised§ & 41 & 29 & $\begin{array}{c}-12 \\
(-20 \text { to }-4)\end{array}$ & $\begin{array}{c}1.79 \\
\text { (1.09 to } 2.94)\end{array}$ & 0.02 & 74 & 61 & $\begin{array}{c}-13 \\
(-21 \text { to }-5)\end{array}$ & $1.3(0.9$ to 1.9$)$ & 0.2 \\
\hline $\begin{array}{l}\text { Mean (SD) No of outpatient } \\
\text { visits? }\end{array}$ & $45.3(26.2)$ & $17.5(26.7)$ & - & - & $<0.001$ & $\begin{array}{l}31.9 \\
(22.9)\end{array}$ & $\begin{array}{l}10.5 \\
(12.2)\end{array}$ & - & $\begin{array}{c}21.2 \\
(17.9 \text { to } 24.4)\end{array}$ & $<0.001$ \\
\hline $\begin{array}{l}\text { Median No of outpatient } \\
\text { contacts*** }\end{array}$ & 42 & 11 & - & - & $<0.001$ & 30 & 7 & - & - & $<0.001$ \\
\hline \multicolumn{11}{|l|}{ During intervention: } \\
\hline Family involved in treatment* & 59 & 18 & $\begin{array}{c}-41 \\
(-49 \text { to }-33) \\
\end{array}$ & $\begin{array}{c}8.3 \\
\text { (5.3 to } 12.5) \\
\end{array}$ & $<0.001$ & 42 & 9 & $\begin{array}{c}-31 \\
(-40 \text { to }-26) \\
\end{array}$ & $\begin{array}{c}9.9 \\
\text { (5.6 to 17.4) }\end{array}$ & $<0.001$ \\
\hline $\begin{array}{l}\text { Family involved in } \\
\text { psychoeducational group* }\end{array}$ & 41 & 1 & $\begin{array}{c}-40 \\
(-46 \text { to }-34)\end{array}$ & $\begin{array}{c}50.0 \\
(16.7 \text { to } 100.0) \\
\end{array}$ & $<0.001$ & 34 & 0.5 & $\begin{array}{c}-34 \\
(39 \text { to }-15)\end{array}$ & $\begin{array}{c}120.2 \\
\text { (16.5 to } 873.9) \\
\end{array}$ & $<0.001$ \\
\hline $\begin{array}{l}\text { Social skills training or } \\
\text { training in daily activities* }\end{array}$ & 37 & 12 & $\begin{array}{c}-25 \\
(-32 \text { to }-18)\end{array}$ & 4.5 (2.9 to 7.7$)$ & $<0.001$ & 24 & 3 & $\begin{array}{c}-21 \\
(-27 \text { to }-15)\end{array}$ & $\begin{array}{c}11.7 \\
\text { (4.9 to } 27.7)\end{array}$ & $<0.001$ \\
\hline \multicolumn{11}{|l|}{ Antipsychotic drug use } \\
\hline 1st or 2nd generation drugs* & 68 & 61 & $-7(-15$ to 1$)$ & $\begin{array}{c}1.4 \\
(1.0 . \text { to } 2.0)\end{array}$ & 0.08 & 60 & 55 & $-5(-14$ to 4$)$ & 1.2 (0.9 to 1.8$)$ & 0.2 \\
\hline 1st generation drugs only ${ }^{*}$ & 15 & 20 & $5(-2$ to 12$)$ & 0.7 (0.5 to 1.1$)$ & 0.1 & 17 & 20 & $3(-4$ to 10$)$ & 0.9 (0.5 to 1.4$)$ & 0.5 \\
\hline 2nd generation drugs only* & 57 & 50 & $-7(-16$ to 2$)$ & 1.4 (1.0 to 1.9$)$ & 0.1 & 49 & 42 & $-7(-16$ to 2$)$ & $1.3(0.9$ to 1.9$)$ & 0.2 \\
\hline \multicolumn{11}{|l|}{$\begin{array}{l}\text { Mean (SD) equivalents of } \\
\text { haloperidol (mg)t†: }\end{array}$} \\
\hline 1st or 2 nd generation drugs & $4.3(3.0)$ & $5.2(3.8)$ & - & $1.0(0.2$ to 1.7$)$ & 0.01 & $4.3(2.8)$ & $5.3(3.4)$ & - & $\begin{array}{c}-0.7 \\
(-1.4 \text { to } 5.6)\end{array}$ & 0.07 \\
\hline 1st generation drugs only & $3.7(2.5)$ & $4.3(4.6)$ & - & $\begin{array}{c}0.5 \\
(-1.1 \text { to } 2.0)\end{array}$ & 0.6 & $3.3(2.7)$ & $3.0(3.4)$ & - & $\begin{array}{c}0.29 \\
(-1.01 \text { to } 1.6)\end{array}$ & 0.7 \\
\hline 2nd generation drugs only & $4.1(2.4)$ & $4.7(2.4)$ & - & 0.6 (0.0 to 1.2$)$ & 0.05 & $4.0(2.4)$ & $4.9(2.9)$ & - & $\begin{array}{c}-0.91 \\
(-1.6 \text { to }-0.2)\end{array}$ & 0.01 \\
\hline
\end{tabular}

*Based on patients with full medical record (507 and 436 for years 1 and 2). Odds ratio and $P$ values based on logistic regression analyses with treatment site as covariate.

†Based on register information (542 and 539 patients for years 1 and 2). Odds ratio and $P$ values based on analysis of variance with treatment site as covariate.

łBased on register information. P values based on Mann-Whitney’s non-parametric test for independent samples.

§Based on register information. Odds ratio and P-values based on logistic regression analyses with treatment site and hospitalised at baseline included as covariates.

IBased on patients with full medical record. Odds ratio and $P$ values based on analysis of variance with treatment site as covariate.

**Based on patients with full medical record. P values based on Mann-Whitney’s non-parametric test for independent samples.

t†ln calculating equivalence, $100 \mathrm{mg}$ chlorpromazine estimated to be equivalent to $2 \mathrm{mg}$ haloperidol. Based on patients with full medical record. Odds ratio and $\mathrm{P}$ values based on analysis of variance with treatment site as covariate.

sor Philip Hougaard supervised the statistical analyses. Runa Munkner and Per Kassow conducted research interviews. The staff at the Copenhagen Trial Unit planned and conducted the randomisation procedure for the Copenhagen patients. All the authors participated in critical revision of drafts for the manuscript and approved the final version. $\mathrm{MN}$ and $\mathrm{PeJ}$ were responsible for designing the study and, together with $\mathrm{PiJ}$ and MA, chose the assessment instruments. PiJ, MA, PeJ, LP, AT, JØ, TØC, and GK conducted the research interviews. MN, LP, AT, and PiJ analysed the data and LP and MN wrote and revised the manuscript. $\mathrm{MN}$ is guarantor for the study.

Funding: The project received grants from the Danish Ministry of Health (jr.nr. 96-0770-71), Danish Ministry of Social Affairs, University of Copenhagen, Copenhagen Hospital Corporation, Danish Medical Research Council (jr.nr. 9601612 and 9900734), and Slagtermester Wørzners Foundation.

Competing interests: None declared.

Ethical approval: The local ethics committee approved the trial (KF 01-387/97).

1 Marshall M, Lockwood A. Assertive community treatment for people with severe mental disorders. Cochrane Database Syst Rev 2000;(2):CD001089.
2 Pharoah FM, Mari JJ, Streiner D. Family intervention for schizophrenia. Cochrane Database Syst Rev 2000;(2):CD000088.

3 Nordentoft M, Laursen TM, Agerbo E, Qin P, Hoyer EH, Mortensen PB. Change in suicide rates for patients with schizophrenia in Denmark, 1981-97: nested case-control study. BMJ 2004;329:261.

4 Birchwood M, Todd P, Jackson C. Early intervention in psychosis. The critical period hypothesis. BrJ Psychiatry Suppl 1998;172:53-9.

5 Jorgensen P, Nordentoft M, Abel MB, Gouliaev G, Jeppesen P, Kassow P. Early detection and assertive community treatment of young psychotics: the opus study rationale and design of the trial. Soc Psychiatry Psychiatr Epidemiol 2000;35:283-7.

6 Roland M, Torgerson DJ. What are pragmatic trials? BMJ 1998;316:285.

7 Stein LI, Test MA. Alternative to mental hospital treatment. I. Conceptual model, treatment program, and clinical evaluation. Arch Gen Psychiatry 1980;37:392-7.

8 McGrew JH, Bond GR, Dietzen L, Salyers M. Measuring the fidelity of implementation of a mental health program model. J Consult Clin Psychol 1994;62:670-8

9 McFarlane WR, Lukens E, Link B, Dushay R, Deakins SA, Newmark M, et al. Multiplefamily groups and psychoeducation in the treatment of schizophrenia. Arch Gen Psychiatry 1995;52:679-87.

10 World Health Organization. WHO Psychiatric Disability Assessment Schedule (WHO/DAS). Geneva: WHO, 1998

11 Liberman RP, Mueser KT, Wallace CJ, Jacobs HE, Eckman T, Massel HK. Training skills in the psychiatrically disabled: learning coping and competence. Schizophr Bull 1986;12:631-47.

12 World Health Organization Division of Mental Health. Schedule for clinical assessment in neuropsychiatry, version 2.1. Present state examination. Geneva: WHO, 1998. 


\section{What is already known on this topic}

Patients with non-affective, first episode psychosis constitute a high risk group for several negative outcomes

Psychoeducational multi-family groups are effective in preventing relapse in populations of patients with chronic schizophrenia

Assertive community treatment of patients with severe mental illness has positive effects on independent living, labour market affiliation, satisfaction with treatment, and use of hospital beds

\section{What this study adds}

Integrated treatment (assertive community treatment enhanced with psychoeducational family intervention and social skills training) can be modified to focus on elements of special relevance to patients with a first episode of psychotic illness

Integrated treatment reduced psychotic and negative symptoms more than standard treatment

Integrated treatment also reduced comorbid alcohol and drug misuse and increased adherence to treatment and user satisfaction

13 Andreasen NC, Olsen S. Negative v positive schizophrenia. Arch Gen Psychiatry 1982;39:789-94.

14 Andreasen NC, Arndt S, Alliger R, Miller D, Flaum M. Symptoms of schizophrenia Methods, meanings, and mechanisms. Arch Gen Psychiatry 1995;52:341-51.

15 Dunn M, O'Driscoll C, Dayson D, Wills W, Leff J. The TAPS project 4: an observational study of the social life of long-stay patients. Br J Psychiatry 1990;157:842-8, 852.

16 Larsen DH, Attkison CC, Hargreaves WA, Nguyen TD. Assessment of client/patien satisfaction: development of a general scale. Eval Progress Planning 1979;2:197-207.

17 Nordentoft M, Jeppesen P, Abel M, Kassow P, Petersen L, Thorup A, et al. OPUS study: suicidal behaviour, suicidal ideation and hopelessness among patients with first-episode psychosis. One-year follow-up of a randomised controlled trial. $\mathrm{Br}$ Psychiatry Suppl 2002;43:s98-106.

18 Hafner H, Riecher-Rossler A, Hambrecht M, Maurer K, Meissner S, Schmidtke A, et al. IRAOS: an instrument for the assessment of onset and early course of schizophrenia. Schizophr Res 1992;6:209-23.
19 Bartko JJ, Carpenter WT Jr. On the methods and theory of reliability. J Nerv Ment Dis 1976;163:307-17.

20 Pocock SJ. Clinical trials. A practical approach. Chichester: John Wiley, 1996.

21 McGorry PD, Edwards J, Mihalopoulos C, Harringan SM, Jackson HJ. EPPIC: an evolving system of early detection and optimal management. Schizophr Bull 1996;22:305-26.

22 Carbone S, Harrigan S, McGorry PD, Curry C, Elkins K. Duration of untreated psychosis and 12-month outcome in first-episode psychosis: the impact of treatment approach. Acta Psychiatr Scand 1999;100:96-104.

23 Malla AK, Norman RM, Manchanda R, McLean TS, Harricharan R, Cortese L, et al. Status of patients with first-episode psychosis after one year of phase-specific community-oriented treatment Psychiatr Serv 2002;53:458-63.

24 Craig TK, Garety P, Power P, Rahaman N, Colbert S, Fornells-Ambrojo M, et al. The Lambeth Early Onset (LEO) Team: randomised controlled trial of the effectiveness of specialised care for early psychosis. BMJ 2004;329:1067.

25 Kjaergard LL, Villumsen J, Gluud C. Reported methodologic quality and discrepancies between large and small randomized trials in meta-analyses. Ann Intern Med 2001;135:982-9.

(Accepted 19 July 2005)

doi 10.1136/bmj.38565.415000.E01

Bispebjerg Hospital, Department of Psychiatry, Bispebjerg Bakke 23, DK-2400 Copenhagen NV, Denmark; and Copenhagen Trial Unit, Centre for Clinical Intervention Research, Rigshospitalet, Copenhagen University Hospital,

Blegdamsvej 9, DK-2100 Copenhagen $\varnothing$, Denmark

Lone Petersen research fellow

Merete Nordentoft associate professor

Bispebjerg Hospital, Department of Psychiatry, Copenhagen NV, Denmark

Pia Jeppesen research fellow

Anne Thorup research fellow

Maj-Britt Abel research fellow

Sct Hans Hospital, DK-4000 Roskilde, Denmark

Johan Øhlenschlæger research fellow

Psychiatric Hospital Risskov, Skovagervej 2, DK-8240 Risskov, Denmark

Torben stergaard Christensen research fellow

Gertrud Krarup chief psychiatrist

Per Jørgensen medical director

Correspondence to: M Nordentoft merete.nordentoft@dadlnet.dk

\section{Amendment}

This is Version 2 of the paper. LP's and MN's affiliation to the Copenhagen Trial Unit has been added, and table 2 has been corrected (the denominator for the standard treatment group at 1 year follow-up changed from 193 to 192). 